\title{
Mutation Analysis Was Not Performed
}

National Cancer Institute

\section{Source}

National Cancer Institute. Mutation Analysis Was Not Performed. NCI Thesaurus. Code C160314.

An indication that mutation analysis was not performed during the study. 